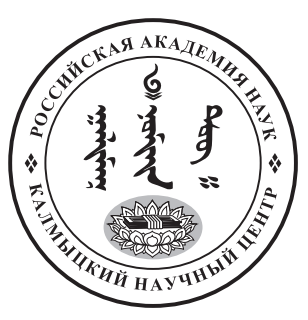

Published in the Russian Federation

Oriental Studies (Previous Name: Bulletin of the Kalmyk Institute

for Humanities of the Russian Academy of Sciences)

Has been issued as a journal since 2008

ISSN: 2619-0990; E-ISSN: 2619-1008

Vol. 14, Is. 4, pp. 797-805, 2021

Journal homepage: https://kigiran.elpub.ru

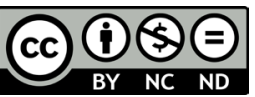

УДК / UDC 94(470.46=512.37)

DOI: $10.22162 / 2619-0990-2021-56-4-797-805$

\title{
Авторские дополнения «Этюдов по истории приволжских калмыков» Н. Н. Пальмова 1929-1932 гг.
}

\section{Александр Викторович Цюрюмов ${ }^{1}$, Андрей Алексеевич Курапов ${ }^{2}$}

${ }^{1}$ Калмыцкий научный центр РАН (д. 8. ул. И. К. Илишкина, 358000 Элиста, Российская Федерация) доктор исторических наук, профессор, ведущий научный сотрудник

iD 0000-0001-8214-3758. E-mail: tsyuryumov@yandex.ru

${ }^{2}$ Калмыцкий научный центр РАН (д. 8. ул. И. К. Илишкина, 358000 Элиста, Российская Федерация) доктор исторических наук, доцент, ведущий научный сотрудник

(iD) 0000-0002-0521-2710. E-mail: akurapov78@rambler.ru

(C) КалмНЦ РАН, 2021

(C) Цюрюмов А. В., Курапов А. А., 2021

Аннотация. Введение. Статья посвящена исследованию авторских дополнений профессора Н. Н. Пальмова, подготовленных в 1929-1932 гг. к «Этюдам по истории приволжских калмыков». Цель исследования - введение в оборот нового рукописного материала профессора Н. Н. Пальмова, позволяющего показать творческие искания ученого и при этом значительно расширить наши представления об истории Калмыцкого ханства; определение хронологических рамок создания авторских дополнений, разделение их на тематические блоки; определение научной значимости ранее неопубликованных материалов. Результаты. В библиотеке Государственного бюджетного учреждения культуры Астраханской области «Астраханский музей-заповедник» авторами статьи выявлен авторский экземпляр «Этюдов по истории приволжских калмыков» Н. Н. Пальмова, на страницах томов I и II сохранились 37 рукописных авторских дополнений 1929-1932 гг., ставшие результатом повторного обращения исследователя к материалам Астраханского калмыцкого архива и научной литературе. Хронология авторских дополнений - от периода добровольного вхождения калмыков в состав России до 60-х гг. XVIII в. В авторских дополнениях содержится ценнейший материал по истории конфликта хана Аюки с сыновьями - усобице 1702 г. Н. Н. Пальмов подробно остановился на феодальном конфликте 1724 г. Автором приведены свидетельства, характеризующие в качестве нойона Дондук-Омбо, в период феодальных войн, а потом хана. Значительный материал посвящен ряду сюжетов по истории внешней политики Калмыцкого ханства, прежде всего истории взаимодействия с Джунгарским ханством в XVII-XVIII вв. Выявленные авторские дополнения на страницах «Этюдов по истории приволжских калмыков» в научной библиотеке Астраханского музея-заповедника значительно расширяют историческую картину периода феодальных усобиц в Калмыцком ханстве в 20-30-х гг. XVIII в. 
Ключевые слова: авторские дополнения, музей, Калмыцкое ханство, феодальные усобицы, зайсанг, нойон, хан

Благодарность. Исследование проведено в рамках государственной субсидии - проект «Комплексное исследование процессов общественно-политического и культурного развития народов Юга России» (номер госрегистрации: АААА-А19-119011490038-5).

Для цитирования: Цюрюмов А. В., Курапов А. А. Авторские дополнения «Этюдов по истории приволжских калмыков» Н. Н. Пальмова 1929-1932 гг. // Oriental Studies. 2021. Т. 14. № 4. C. 797-805. DOI: 10.22162/2619-0990-2021-56-4-797-805

\title{
Essays on the History of the Volga Kalmyks by N. N. Palmov: Author's Additions, 1929-1932
}

\author{
Alexander V. Tsyuryumov ${ }^{1}$, Andrew A. Kurapov ${ }^{2}$ \\ ${ }^{1}$ Kalmyk Scientific Center of the RAS (8, Ilishkin St., 358000 Elista, Russian Federation) \\ Dr. Sc. (History), Professor, Leading Research Associate \\ (iD) 0000-0001-8214-3758. E-mail: tsyuryumov@yandex.ru \\ ${ }^{2}$ Kalmyk Scientific Center of the RAS (8, Ilishkin St., 358000 Elista, Russian Federation) \\ Dr. Sc. (History), Associate Professor, Leading Research Associate \\ iD 0000-0002-0521-2710. E-mail: akurapov78@rambler.ru \\ (C) KalmSC RAS, 2021 \\ (C) Tsyuryumov A. V., Kurapov A. A., 2021
}

\begin{abstract}
Introduction. The article examines additional comments (1929-1932) made by Professor N. N. Palmov on his Essays on the History of the Volga Kalmyks (1926). Goals. The study seeks to introduce this new material which shows the scholar's persistent interest in the subject and, at the same time, contributes to a better understanding of the history of the Kalmyk Khanate. Materials and Methods. The research involved the identification of the chronological framework of the handwritten material, its categorization into thematic blocks, and contribution to the subject. Results. In the library of Astrakhan State Museum of Historical Archives, the authors discovered thirty seven handwritten additions made by Palmov on the pages of his copy of Essays on the History of the Volga Kalmyks, vols. I-II. These were made between 1929 to 1932 when the scholar apparently continued his studies on the subject using the materials of Astrakhan Kalmyk Archives and scientific literature. The author's comments covering the period up to the 1760s contain valuable data on the 1702 conflict between Khan Ayuka and his sons and provide detail on the feudal conflict of 1724. Also, Palmov provides additional evidence on Noyon Donduk-Ombo's activities during the period of feudal wars and, later, when he was Kalmyk Khan. Finally, the comments include important data on the foreign policy of the Kalmyk Khanate, chiefly the history of its interaction with the Dzungar Khanate in the $17^{\text {th }}-18^{\text {th }}$ centuries. Conclusions. Palmov's handwritten comments discovered on the pages of his Essays on the History of the Volga Kalmyks are a significant contribution to his scientific heritage that sheds light on the history of feudal strife in the Kalmyk Khanate in the 1720s-1730s.

Keywords: author's additional comments, Astrakhan State Museum of Historical Archives, Kalmyk Khanate, feudal strife, zaisang, noyon, khan

Acknowledgements. The reported study was funded by government subsidy, project no. AAAA-A19-119011490038-5 'Sociopolitical and Cultural Development of South Russia's Peoples: Comprehensive Studies of Respective Processes'.

For citation: Tsyuryumov A. V. Kurapov A. A. Essays on the History of the Volga Kalmyks by N. N. Palmov: Author's Additions, 1929-1932. Oriental Studies. 2021. Vol. 14 (4): 797-805. (In Russ.). DOI: 10.22162/2619-0990-2021-56-4-797-805
\end{abstract}




\section{Введение}

Среди астраханских исследователей-калмыковедов первой трети XX в. большую известность получил профессор Астраханского государственного университета Николай Николаевич Пальмов (1872-1934). Н. Н. Пальмов закончил Киевскую духовную академию, стал заведующим кафедрой, профессором и после возвращения в Астрахань в 1918 г. был назначен профессором местного университета. В 1921 г. он был назначен заведующим архивно-музейной секцией при отделе народного образования Калмыцкой автономной области [Матвенов 2009: 112-113].

Занимаясь упорядочением, систематизацией и описанием архивных документов, Н. Н. Пальмов соприкоснулся с архивными источниками и начал изучение калмыцкой истории. Краеведческий музей в Элисте был создан при его участии 23 марта 1921 г., с 1922 г. Н. Н. Пальмов стал руководителем основанного им музея. В конце 1923 г. он стал заведующим архивным бюро при Центральном исполнительном комитете Калмыцкой автономной области [Боликова 2017: 182].

До 1934 г. Н. Н. Пальмов опубликовал целый ряд основополагающих работ по истории калмыков [Пальмов 1922; Пальмов 1924; Пальмов 1926; Пальмов 1928].

В Национальном архиве Республики Калмыкия существует фонд Р-145 с личными документами, опубликованными и неопубликованными рукописями выдающегося ученого. В связи с этим интерес представляет дальнейший поиск неизвестных рукописей историка. В библиотеке Астраханского музея-заповедника авторами статьи был выявлен авторский экземпляр «Этюдов по истории приволжских калмыков», на страницах томов I и II сохранились авторские дополнения, выполненные Н. Н. Пальмовым.

Цель исследования состояла во введении в научный оборот неизвестного ранее рукописного материала профессора Н. Н. Пальмова, который позволяет определить направление развития научной мысли ученого, расширить сложившиеся представления об истории Калмыцкого ханства, в определении хронологических рамок создания авторских дополнений, разделение дополнений на тематические блоки, опре- деление их научной значимости. В качестве исследовательских авторы поставили перед собой следующие задачи: на основе авторских материалов, выявленных и исследованных в научной библиотеке Астраханского музея-заповедника, раскрыть значение авторских дополнений для историографии Калмыцкого ханства и исследования исторического наследия Н. Н. Пальмова.

\section{Материалы}

Основным материалом к статье стали 37 рукописных дополнений к I и II тому «Этюдов по истории приволжских калмыков» Н. Н. Пальмова, выявленных авторами статьи в научной библиотеке Астраханского музея-заповедника, хронологические рамки которых - период добровольного вхождения калмыков в состав России до 60-х гг. XVIII в. в истории Калмыцкого ханства.

Авторские дополнения Н. Н. Пальмова к «Этюдам по истории приволжских калмыков»

Оценивая степень изученности исторического наследия Н. Н. Пальмова, необходимо отметить значительный интерес историков к его жизни, историческим трудам, деятельности в рамках архивной и музейной работы. Историография вопроса представлена исследованиями по биографии Н. Н. Пальмова [Джалаева 2003; Джумалиева 2003; Пальмов 2006; Бадмаев 2013; Сухова 2015], по его вкладу в развитие архивного и музейного дела Республики Калмыкия [Санджиева 2003; Шалданова 2003; Матвенов 2009; Боликова 2017; Бураковская 2017], по основным направлениям его научной работы [Бадмаев 2013; Джагаева 2013; Курапов 2018].

37 рукописных авторских дополнений Н. Н. Пальмова к I и II тому «Этюдов по истории приволжских калмыков» являются тематическими выписками из архивных материалов с указанием номера дела Астраханского калмыцкого архива, года и листа, выписками из работ востоковедов XIX в. Объем отрывков - от четверти до нескольких страниц, исписанных мелким почерком Н. Н. Пальмова. На некоторых страницах сохранились сведения о времени создания выписок. Самая ранняя датирована 31 июля 1929 г., самая поздняя - 16 августа 1932 г. Общий объем авторских дополнений Н. Н. Пальмова - около 0,5 авторского ли- 
ста. Таким образом, выписки стали, вероятно, результатом повторного обращения исследователя к материалам указанного архива и научной литературе. При наличии значительного объема работ по биографии Н. Н. Пальмова, его историческим исследованиям, представляет интерес ввод в научный оборот неопубликованных ранее авторских дополнений к «Этюдам по истории приволжских калмыков».

Выписки Н. Н. Пальмова, помещенные в экземпляры «Этюдов», хранившиеся в научной библиотеке Астраханского музея-заповедника, можно разделить на несколько тематических блоков, большая часть которых относится к тому I.

Говоря о периоде вхождения калмыков в состав России, Н. Н. Пальмов приводит текст письма нойона Байсхалантун Убаши астраханскому губернатору Н. А. Бекетову (1765 г.), в котором тот сообщал, что «прадед мой Лоузан, как еще на Волге ни один калмык не бывал, то он, Лоузан, с улусами своими во первых к реке Волге прикочевал, в подданство российских государей вступя, обратно послал посланцов с увещанием к призыву и объявлением своего совета, потому и прочие калмыки прикочевали» [Пальмов 1926: 5].

На страницах обоих томов Н. Н. Пальмов поместил новые материалы по истории конфликта хана Аюки с сыновьями, известного как усобица 1702 г. Например, 1 июля 1745 г. Дондук-Даши рассказал о заслугах отца: «Когда нашего хана дети пришли в возраст, и когда Дондук-Омбин отец Гунджап, будучи у него в особливой милости, и вознамерясь все наши улусы один взять в свою власть, старшему своему брату, а моему отцу давал отраву, и пострелил его из пищали двумя пулями, и тем улусы наши привел в смятение. Но боги отца моего за невинность его от того исцелили, и все торгуды ... при задержании хана пристали к отцу моему, а Гунжап, по учиненной его противности, не мог более в улусах быть, но принужден был уйти в Саратов. А напоследок и все торгуды перешли за р. Яик, желая отойти на прежне жилище. Тогда отец мой, нехотя отъезжать ... большую часть улусов из-за Яика от р. Темиря возвратил и привел сюда», а ... если бы Чакдоржап не пришел обратно, то «волжских и яицких торгудов имени уже не было» (79 об.) [Пальмов 1926:
88]. Тогда Б. А. Голицын «заставил Чакдоржапа на коленях вымаливать у виновного отца прощения себе» [Пальмов 1926: 88].

Приведенные выше материалы значительно дополняют картину событий, предложенную ранее [Цюрюмов 2007: 148-153].

Дополнил это сообщение посланец владельца Хошот Дондука Дурал-Хошочий, привезший 29 августа 1724 г. письмо нойона А. П. Волынскому: «В прошлых годех ${ }^{1}$ (когда у хана Аюки с сыном его, Чакдоржапом была ссора) Чакдоржап с улусом своим откочевал за Яик, ... куда и брат его Санджип бродил, и владелец де его, Дондук, его Чакдоржапа до того не допустил и паки привел его под владения ханские. Так же во время астраханского бунту он же, Хошот Дондук, и с российскими и со своими войсками штурмом взяли Красный Яр» [Пальмов 1927: 214].

Более подробно Н. Н. Пальмов остановился на знаменитой усобице 1724 г., которой, кстати, посвящена значительная часть «Этюдов». Внимания заслуживает описание церемонии получения ханского звания Церен-Дондуком, которое от имени Далай-ламы вручал 10 сентября 1725 г. Шакур-лама. У Н. Н. Пальмова данный документ назван «Записка бывшей у хана Черен-Дондука церемонии, как данной ему от Далай-ламы ханской чин от Шакур-ламы в народ публикован» [Пальмов 1926: 98].

Сначала автор описывает ханскую кибитку и первые действия церемонии:

«Убрана была ево ханская кибитка по калмыцкому обычаю всяких разных парчой убором, и сделано ему, хану сидеть особенное место. А ниже ево, по правую сторону другое место - Шакур-ламе. В другой кибитке убраны были их бурханы, и несколько при том их духовного чина людей чинили по своему заодно, которое прислано ему во знак ханства от далай-ламы, называемое тук, а другое, данное Намки-гелену от бурхана Чоичинга. Помянутые духовного чина люди по тому ж, как и Шакур-ламу, всем собранием тако ж со знамены, и с трубами, и с колоколами, и с великим пением встретили. И как он, батур-гелень приехал ко дверям ханской кибитки, слез с лошади, так и прочие все, которые за ним ехали, слезли же и пошли друг за другом в кибитку. И Шакур-лама встал на ноги, принял грамо-

1 Здесь и далее орфография и пунктуация источника сохранены. 
ту и положил себе на голову, а потом принял платье и надел на хана. И как ево, хана, в помянутое платье убрал, по тому он, хан, сел. А Шакур-лама оную Далай-ламину грамоту тангутским диалектом читал прежде в кибитке ханской. И потом, вышел из кибитки, читал всенародно. А знамена поставлены были у дверей, а ружье, сайдак и саблю держали при лошади. Как он, Шакур-лама, всему народу грамоту прочел, то все калмыки подходили к нему по одному, и он помянутую грамоту клал каждому на голову и, вшед в кибитку, хана поздравлял.

При том были мать ево, ханша Дарма-Бала, и брат Галдан-Данжин, ево ханская жена Деджит, и жена брата ево, и прочие зайсанги. И между собою они, хан, ханша, Галдан-Данжин и лама друг друга дарили китайскими платками и некоторыми вещицами.

Потом он, хан, вышел из кибитки, подпоясал на себя присланной от далай-ламы сайдак и саблю и сел на лошадь, ездил к бурханской кибитке, куда приехал, слез и ходил в ту кибитку и кланялся всем бурханам по своему обычаю, а ружье за ним носили. И как он, хан, из той кибитки вышел, паки сел на лошадь, по тому ж поехал к своей кибитке. И приехав, слезли с лошади, вшед в кибитку, сел на помянутом ему устроенном месте. И стали пить вино, и играть в свои музыки.

Помянутые их духовного чина люди чрез все то время стояли в две линии, с трубным гласом и с колокольным звоном чинили пение. Он, хан, чрез весь тот день сидел во своем том уборе на том месте, никуда не вставая. А чрез плечи у него, хана, положен был белой китайской сырцовый платок» [Пальмов 1926: 98].

Примерно на тех же деталях более подробно останавливался М. М. Батмаев [Батмаев 2002].

Далее автор перечисляет зайсангов, получивших награды. Были выделены «ханские ближние и первые советники» [Пальмов 1926: 98], упомянут среди награжденных «ево ханской камардин дядька» и «жены ево ханской Деджита камордином», а также «всему калмыцкому народу урядчик служитель ево ханской», а также «командир над придворники» [Пальмов 1926: 98].

Н. Н. Пальмов упоминает, что во время церемонии при хане находился дворянин Спиридон Везелев, которого хан, призывал к себе в кибитку и объявил, что сначала он пожалован ее императорским величеством ханом, а теперь и Далай-ламой пожалован ханским чином, грамотой, знаменем и «ханским убором и сбруей», и дано ему звание Шаса Бодж Дайчин хан [Пальмов 1926: 98-99].

Профессор Н. Н. Пальмов привел несколько свидетельств, характеризующих нойона Дондук-Омбо. Например, он приводит свидетельство калмыка из улуса Баксадай Доржи о том, что после перехода через линию ${ }^{2}$ Дондук-Омбо приезжал к ханше и хотел на ней жениться. Но, получив отказ, он заявил, что, лишь послушав ханшу, перешел через линию, теперь он будет думать об уходе [Пальмов 1926: 68].

Вероятно, это и стало причиной охлаждения их отношений. 4 июня зайсанг Хашха сообщал, что Дондук-Омбо, приехав к лекарю под предлогом лечения, не поехал к Дарма-Бале, от которой лекарь кочевал в верстах 20, несмотря на то, что она его «звала к себе многократно для совету» по поводу опасений ввиду слухов, связанных с ожидавшимся приездом Волынского [Пальмов 1926: 68].

Немало интересных свидетельств были выявлены по истории правления хана Дондук-Омбо. Продолжали ухудшаться его отношения с Дарма-Балой. В письме, поданном императрице 16 ноября 1733 г., Дарма-Бала жаловалась: «А моих собственных улусов половину, и другие вещи - злато и сребро, корольки и жемчуг, и прочей весь мой багаж без остатки взял Дондук-Омбо» [Пальмов 1926: 100].

2 января 1735 г. донской старшина Д. Ефремов привез императрице письмо Дондук-Омбо. В нем он сообщал, что «хон-тайшин сын Галдан-Черен» предлагал Церен-Дондуку арестовать нойона и Лоузан-Шоно [Пальмов 1926: 68]. Это же предлагал и Дондук-Даши. Письма были обнаружены в ставке Церен-Дондука [Пальмов 1926: 68].

История отношений Дондук-Омбо и его сына Галдан-Нормо была рассмотрена в ряде статей [Цюрюмов 1998: 14-16; Цюрюмов 2007: 182-244]. Но в дополнениях Н. Н. Пальмова обнаружился ряд новых сведений. Например, он пишет, что 27 августа 1739 г. по приказу Коллегии иностранных дел царицынский комендант полковник Кольцов встретился с содержащимся в Ца-

\footnotetext{
2 Речь идет о Царицынской линии.
} 
рицыне Галдан-Нормо. Ханский сын рассказал, что летом 1738 г. перед походом на казахов знатный зайсанг Джан-Булат, «которой всегда во всяких секретах при отце ево находится», секретно предупредил, что «отец ево, хан Дондук-Омбо, подлинно имеет намерение ево, Галдан-Норму, поймав, умертвить» [Пальмов 1926: 90].

Когда поход начался, хан Дондук-Омбо приказал нойонам Нинкбе, сыну Бокшурги, Лабанг-Дондуку, сыну Четеря, арестовать Галдан-Нормо.

Но «он, Галдан-Нормо, видя от отца своего такое злое к себе намерение, к отцу своему не возвратился, рассуждая, что ежели ему к нему возвратиться, то оной отец ево в такой горячести может ево умертвить, и положил намерение с оставшими при нем войск итти на касак, дабы между того, продолжая время, отца своего гнев отменить. И будучи в том касацком походе, и возвратился ко отцу своему, точно ево уже на луговой стороне и со всеми улусами не получил, похоже он, хан, во отбытие ево переправился на нагорную сторону; того ради он, Галдан-Норбо, остановился на луговой стороне, имел с отцом своим и пересылки, между которыми приехали к нему с грамотой ее императорского величества донского войскового атамана Данилы Ефремова сын Степан Ефремов, а с присягою от отца ево знатные и объявили ему, что отец ево, хан Дондук-Омбо во всем вину ему отпущает, которой он, Галдан-Норбо, за собою как прежде не признавал, так и ныне не признавает, чего для с грамотою ее императорского величества старшина Степан Ефремов, а с верною ево ханскою присягой они, зайсанги, к нему и присланы, и чтоб он, Галдан-Норбо, в начале грамоте ее императорского величества, також и присяги отца своего поверил и без всякой опасности обще с ними к отцу своему ехал. По которому их объявлению, он, Галдан-Норбо, как грамоте ее императорского величества, так и присяге отца своего поверя, с помянутыми старшиною Степаном Ефремовым и присланными зайсанги к отцу своему на нагорную сторону переехав, и ему явился, которой и персонально ему сказал, что вина ево отпущается, точно он никакой вины за собою не признавал и потом он, Галдан-Норбо, с того время даже до поимки своей, жил при улусах своих и кочевал обще с отцом своим, а злого намерения как прежде, так и по прибытии из касацкого похода на отца своего не имел. А ныне оной отец ево за что поймав и ему, полковнику, отдал, про то не ведает, ибо он, Галдан-Норбо, пред отцом своим никакой вины не признавает, что оное ему учинилось по навету мачехи своей для того, что в бытность ево при улусах своих сказывал ему один знатный зайсанг, который всегда при отце и при мачехе ево обретается неотлучно, что де от отца твоего к тебе никакого зла не признавается, а мачеха де твоя конечно некоторое зло на тебя в мысли своей имеет, что он, Галдан-Норбо, за подлинно ныне и признавает, что оное ему учинилось по навету мачехи ево» [Пальмов 1927: 90].

Полковник Кольцов посоветовал Галдан-Норме согласиться с приказом императрицы отправиться в г. Казань [Пальмов 1927: 34, 91].

Самый объемный материал посвящен некоторым сюжетам по истории внешней политики ханства, прежде всего истории отношений с Джунгарским ханством. Как пишет Н. Н. Пальмов, С. Казанцев, будучи в калмыцких улусах, узнал, что после смерти джунгарского хунтайджи его младшая жена, дочь хана Аюки, была убита, а два ее сына «отданы в Бухару также де и посланцов Церен-Дондуковых побили» [Пальмов 1926: 68].

События в Джунгарии стали причиной того, что казахи «собрались и для жития пришли в старые свои места и пошли войною на хон-тайшино жилище и ... калмык и побрали, что слыша здешние калмыцкие владельцы хотят итти на Кубань» [Пальмов 1926: 68].

Автор вновь обращается к судьбе посольства 1729 г. Он привел свидетельство о том, что посланцам Церен-Дондука 24 ноября 1734 г. было сообщено в Коллегии иностранных дел: «О посланцах ваших, отправленных к далай-ламе, Намки-гелене с товарищи пред недавным временем чрез бывшего в Пекине российского курьера получено здесь известие, что оные, по отъезде ево оттуды, остались ещё в Пекине» [Пальмов 1926: 96].

Особое внимание автора вызвало выяснение судьбы подарков, отправленных Дондук-Омбо китайскому императору. Подполковник кизлярской нерегулярной команды Расланбек Шейдяков 9 декабря 1749 г. подал Бестужеву-Рюмину письмо Дондук Даши от 26 октября того же года. В нем сообщалось, что Дондук-Омбо послал в пода- 
рок «хорошим убором оправленную одну турецкую пищаль и одни золотые часы» [Пальмов 1926: 250].

Подарки были отданы посланцем Джимба-Джамсой иркутскому губернатору «для спасения живота своего» [Пальмов 1926: 250].

О них-то и писал Дондук-Даши, прося вернуть их ему «по той причине, что и прочие Дондук-Омбины таковые вещи от государыни всемилостивейше мне пожалованы, и потому Вас покорно прошу милостиво приказать оные вещи отыскать и ко мне переслать» [Пальмов 1926: 250].

Судьбу подарков начал выяснять канцлер: 23 января 1751 г. он написал наместнику, что иркутскому вице-губернатору Лангу 31 декабря 1750 г. отправлен ее императорского величества указ «не умедля» сообщить о судьбе ружья и часов [Пальмов 1926: 250].

12 марта 1751 г. последовал указ Коллегии иностранных дел, что от иркутского вице-губернатора от 5 августа и от 13 ноября получены доношения, «которыми он представляет, что помянутые ружье и часы посланцом Джимбо Джамсою ему, Лангу, подарены добровольно, без всякого принуждения, и при оных часы и ружье прислал сюда. И хотя те часы, по-видимому, не только не большой цены, но и во употребление непрочны, однако ж оные здесь починены и посылаются обще с ружьем к вам (Спицыну) при сем указе, а вы имеете их к нему, наместнику, от себя отослать, уведомляя его о том по содержанию сего ука-

\section{Литература}

Бадмаев 2013 - Бадмаев Б. В. Становление профессора Н. Н. Пальмова как ученого-исследователя // Вестник Прикаспия: археология, история, этнология. 2013. № 4. С. 89-92.

Батмаев 2002 - Батмаев М. М. Социально-политический строй и хозяйство калмыков в XVII-XVIII вв. Элиста: КГУ, 2002. 400 с.

Боликова 2017 - Боликова Р. Б. Становление архивной службы в Калмыкии в период 1918-1934 гг. // Великая Российская революция в судьбах народов Юга России. Мат-лы всеросс. науч. конф. (с междунар. участием), посвященной 100-летию революции 1917 года. Элиста: КалмНЦ РАН, 2017. С. 179-189. за» [Пальмов 1926: 250]. Часы и ружье отосланы Спицыным наместнику 2 мая 1752 г. [Пальмов 1926: 250].

Уважаемый автор вносит ясность в вопрос об инициаторах откочевки 1771 г., । отметив, что в марте 1769 г. Оренбургский губернатор И. А. Рейнсдорп получил сведения о сношениях Шеаренга с казахами в целях присоединения к ним и сообщает о том И. А. Кишненскому, но последний не поверил слухам и посчитал их вымыслом. Он больше склонен допускать возможность сношения владельца Замьяна с казахами [Пальмов 1927: 188].

\section{Выводы}

Выявленные авторские дополнения на страницах экземпляра «Этюдов по истории приволжских калмыков» в научной библиотеке Астраханского музея-заповедника, значительно расширяют историческую картину событий в Калмыцком ханстве. Особенно значительный материал уважаемый исследователь выявил по истории изучения усобиц в послеаюкинский период накануне вступления на престол Церен-Дондука, и усобицы, развернувшейся в годы правления Дондук-Омбо. Данная особенность вообще характерна пальмовским «Этюдам», значительный объем которых посвящен калмыцким междоусобицам. Кроме этого, в дополнениях мы находим ценное описание церемонии принятия ханского титула от Далай-ламы. Не сомневаемся, что данная работа вызовет интерес исследователей истории Калмыцкого ханства и может быть опубликована отдельным изданием.

Бураковская 2017 - Бураковская М. С. Из истории основных направлений работы Национального архива Республики Калмыкия в 1920-1938 гг. // Oriental Studies. 2017. № 5. C. 74-81. DOI: 10.22162/2075-7794-2017-335-74-81

Джагаева 2013 - Джагаева О. А. О научной и педагогической деятельности профессора Н. Н. Пальмова // Вестник Калмыцкого института гуманитарных исследований РАН. 2013. № 1. C. 32-35.

Джалаева 2003 - Джалаева А. М. К биографии профессора Н. Н. Пальмова // Пальмовские чтения: к 130-летию со дня рожд. проф. Н. Н. Пальмова, организатора архивного и музейного дела Республики Калмыкия: 
мат-лы регион. науч.-практ. конф. (г. Элиста, 9-10 июня 2003 г.). Элиста: [б. и.], 2003. C. $54-60$.

Джумалиева 2003 - Джумалиева А. Б. Памяти Н. Н. Пальмова посвящается // Пальмовские чтения: к 130-летию со дня рожд. проф. Н. Н. Пальмова, организатора архивного и музейного дела Республики Калмыкия: мат-лы регион. науч.-практ. конф. (г. Элиста, 9-10 июня 2003 г.). Элиста: [б. и.], 2003. C. $61-65$.

Курапов 2018 - Курапов A. A. Н. Н. Пальмов о буддийском духовенстве калмыков в XVII-XVIII вв. // Вестник Калмыцкого государственного университета. 2018. № 2. C. $19-25$.

Матвенов 2009 - Матвенов Е. Р. Организация и начало функционирования Калмыцкого краеведческого музея в 1921-1929 годы // Вестник института (ИКИАТ). 2009. № 2. C. 111-114.

Пальмов 1922 - Пальмов Н. Н. Очерк истории калмыцкого народа за время его пребывания в пределах России. Астрахань: Калмгосиздат, $1922.137 \mathrm{c}$.

Пальмов 1924 - Пальмов Н. Н. К истории рыбной промышленности в Астраханском крае в первой половине XVIII века // Наш край. 1924. № 4. С. 113-135.

Пальмов 1926 - Пальмов Н. Н. Этюды по истории приволжских калмыков: в 5 ч. Астрахань: Изд-во Калмоблисполкома, 1926. Ч. 1. $260 \mathrm{c}$.

Пальмов 1927 - Пальмов Н. Н. Этюды по истории приволжских калмыков: в 5 ч. Астрахань: Изд-во Калмоблисполкома, 1927. Ч. 2. $231 \mathrm{c}$.

Пальмов 1928 - Пальмов Н. Н. К астраханскому периоду жизни В. Н. Татищева // Изве-

\section{References}

Badmaev B. V. The shaping of Professor N. N. Palmov as a scholar and researcher. Vestnik Prikaspiya: arkheologiya, istoriya, etnologiya. 2013. No. 4. Pp. 89-92. (In Russ.)

Batmaev M. M. The Kalmyks, $17^{\text {th }}-18^{\text {th }}$ Centuries: Sociopolitical System and Economy. Elista: Kalmyk State University, 2002. 400 p. (In Russ.)

Bolikova R. B. The development of Kalmykia's archival service, 1918-1934. In: The Great Russian Revolution in Destinies of South Russia's Peoples. Jubilee conference proceedings. Elista: Kalmyk Scientific Center (RAS), 2017. Pp. 179-189. (In Russ.) стия Академии наук СССР. Отд. гуманитарных наук. Сер. 7. 1928. № 4-7. С. 317-342.

Пальмов 2006 - Пальмов Николай Николаевич (1872-1934) // Ученые-исследователи Калмыкии (XVII - начало XX вв.): Биобиблиографический указатель / сост. и предисл. П. Э. Алексеевой и Л. Ю. Ланцановой. Элиста: Калм. кн. изд-во, 2006. С. 172-176.

Санджиева 2003 - Санджиева Г. С. Роль Н. Н. Пальмова в организации архивного дела // Пальмовские чтения: к 130-летию со дня рожд. проф. Н. Н. Пальмова, организатора архивного и музейного дела Республики Калмыкия: мат-лы регион. науч.-практ. конф. (г. Элиста, 9-10 июня 2003 г.). Элиста: [б. и.], 2003. С. 261-266.

Сухова 2015 - Сухова Н. Ю. Учитель и ученик: письма 1897-1914 гг., связующие А. А. Дмитриевского и Н. Н. Пальмова // Вестник Екатеринбургской духовной семинарии. 2015. Вып. 4 (12). С. 164-241.

Цюрюмов 1998 - Цюрюмов А. В. Дондук-Омбо и политическая история Калмыцкого ханства // Исторические личности России. Матлы XI Всеросс. науч. конф. (г. Санкт-Петербург). СПб.: Нестор, 1998. С. 14-16.

Цюрюмов 2007 - Цюрюмов A. В. Калмыцкое ханство в составе России: проблемы политических взаимоотношений. Элиста: Джангар, 2007. 464 c.

Шалданова 2003 - Шалданова Л. Б. Роль профессора Н. Н. Пальмова в становлении и развитии архивной службы, музейного дела и исторической науки Калмыкии (к 130-летию со дня рождения) // Пальмовские чтения: к 130-летию со дня рожд. проф. Н. Н. Пальмова, организатора архивного и музейного дела Республики Калмыкия: мат-лы регион. науч.-практ. конф. (г. Элиста, 9-10 июня 2003 г.). Элиста: [б. и.], 2003. С. 8-12.

Burakovskaya M. S. The National Archive of Kalmykia: excerpts from the history of its key activities in 1920-1938. Oriental Studies. 2017. No. 5. Pp. 74-81. (In Russ.) DOI: 10.22162/2075-7794-2017-33-5-74-81

Dzhagaeva O. A. About scientific and pedagogical activity of Professor N. N. Palmov. Bulletin of the Kalmyk Institute for Humanities of the RAS (Oriental Studies). 2013. No. 1. Pp. 32-35. (In Russ.)

Dzhalaeva A. M. Some additions to the biography of Professor N. Palmov. In: The Palmov Readings. Jubilee conference proceedings (Elista; June 9-10, 2003). Elista, 2003. Pp. 54-60. (In Russ.) 
Dzhumalieva A. B. In memory of N. Palmov. In: The Palmov Readings. Jubilee conference proceedings (Elista; June 9-10, 2003). Elista, 2003. Pp. 61-65. (In Russ.)

Kurapov A. A. N. N. Palmov on Kalmyk Buddhist clergy in the XVII-XVIII centuries. Bulletin of Kalmyk University. 2018. No. 2. Pp. 19-25. (In Russ.)

Matvenov E. R. Kalmykia Museum of Local History, Nature and Lore: formation and early activities, 1921-1929. Vestnik instituta (IKIAT). 2009. No. 2. Pp. 111-114. (In Russ.)

Palmov N. N. A history of fishing industry in Astrakhan lands, early-to-mid $18^{\text {th }}$ century. Nash kray. 1924. No. 4. Pp. 113-135. (In Russ.)

Palmov N. N. Kalmyks within Russia's Borders: A Historical Essay. Astrakhan: Kalmyk Oblast Publ. House, 1922. 137 p. (In Russ.)

Palmov N. N. Revisiting the Astrakhan period of V. N. Tatishchev's life. Izvestiya Akademii nauk SSSR. Otd. gumanitarnykh nauk. 1928. No. 4-7. Pp. 317-342. (In Russ.)

Palmov N. N. The Volga Kalmyks: Historical Essays. In 5 vols. Astrakhan: Kalmyk Oblast Executive Committee, 1926. Vol. 1. 260 p. (In Russ.)

Palmov N. N. The Volga Kalmyks: Historical Essays. In 5 vols. Astrakhan: Kalmyk Oblast Executive Committee, 1927. Vol. 2. 231 p. (In Russ.)
Palmov, Nikolay Nikolayevich (1872-1934). In: Alekseeva P. E., Lantsanova L. Yu. Scholarly Researchers of Kalmykia, $17^{\text {th }}$ to Early $20^{\text {th }}$ Centuries. Biographical and bibliographical guide. Elista: Kalmykia Book Publ., 2006. Pp. 172-176. (In Russ.)

Sandzhieva G. S. N. Palmov's role in the arrangement of Kalmykia's archival service. In: The Palmov Readings. Jubilee conference proceedings (Elista; June 9-10, 2003). Elista, 2003. Pp. 261-266. (In Russ.)

Shaldanova L. B. Professor N. Palmov's role in the shaping and development of Kalmykia's historical science, archival and museum services: celebrating the $130^{\text {th }}$ birthday. In: The Palmov Readings. Jubilee conference proceedings (Elista; June 9-10, 2003). Elista, 2003. Pp. 8-12. (In Russ.)

Sukhova N. Yu. The teacher and the pupil: some letters from 1897 to 1914, connecting Alexey A. Dmitrievsky with Nicholas N. Palmov. Bulletin of the Ekaterinburg Theological Seminary. 2015. No. 4 (12). Pp. 164-241. (In Russ.)

Tsyuryumov A. V. Donduk-Ombo political history of Kalmyk Khanate. In: Historical Figures of Russia. Conference proceedings. St. Petersburg: Nestor, 1998. Pp. 14-16. (In Russ.)

Tsyuryumov A. V. Kalmyk Khanate as Part of Russia: Issues of Political Interaction. Elista: Dzhangar, 2007. 464 p. (In Russ.) 